\title{
Las técnicas de reproducción humana asistida desde los derechos humanos como perspectiva obligada de análisis*
}

\section{Agustina Bladilo** \\ Natalia de la Torre ${ }^{* * *}$ \\ Marisa Herrera ${ }^{* * * *}$}

\section{RESUMEN}

En el marco de los derechos sexuales y reproductivos, las técnicas de reproducción humana asistida comprometen la satisfacción de un conjunto de derechos humanos fundamentales, lo que implicó, necesariamente, que su análisis caiga bajo la órbita de la perspectiva del Derecho Internacional de los Derechos Humanos. En esta lógica, el trabajo se propone sentar las bases minimas para estructurar y evaluar legislaciones, politicas públicas y acciones estaduales en este dinámico y complejo

PALABRAS CLAVE: Reproducción Asistida, Derechos Humanos, Jurisprudencia convencional, Bases legales

\begin{abstract}
Within the sexual and reproductive rights framework, assisted human reproduction techniques involve the satisfaction of fundamental human rights, what implied necessary that its analysis falls under the perspective of international human rights law. The work proposes to establish the minimum bases to structure and evaluate legislations, public politics and state actions in this dynamic and complex field of study.
\end{abstract}

KEY WORDS: Assisted reproduction, human rights, conventional jurisprudence, legal bases

\footnotetext{
- Artículo recibido el 23 de Agosto de 2016 y aceptado el 11 de octubre de 2016

" Abogada (UBA). Integrante del proyecto de investigación Ubacyt 2013-2016, "Hacia una ley integral de técnicas de reproducción humana asistida. Bioética y derechos humanos y familias", dirigido por Marisa Herrera. agustinabladilo90@gmail.com

-.- Abogada (UBA). Profesora de Filosofia (UBA). Integrante del proyecto de investigación Ubacyt 2013-2016, "Hacia una ley integral de técnicas de reproducción humana asistida. Bioética y derechos humanos y familias", dirigido por Marisa Herrera. delatorre.natalia@gmail.com

-- Doctora en Derecho (UBA). Investigadora independiente del Conicet. Profesora de Derecho de Familia y Sucesiones, Facultad de Derecho, UBA. marisaherrera12@gmail.com
} 


\section{SUM ARIO}

1. Introducción

2. Las técnicas de reproducción humana asistida como vía para el ejercicio y satisfacción de los derechos humanos

3. Una voz autorizada: la Corte Interamericana de Derechos Humanos

4. Diálogo transatlántico

5. Palabras de cierre

\section{Introducción}

Las técnicas de reproducción humana asistida (TRHA) integran la extensa, compleja y relativamente nueva disciplina denominada bioética. ${ }^{1}$ La vinculación entre bioética y derechos humanos bien puede derivarse de la definición originaria que se le concedió. Se entiende a la bioética "como puente entre ciencias experimentales y humanidades". Actualmente, la concepción de "humanidades" se ha visto engrosada con los aportes de la doctrina internacional de los derechos humanos. Ésta gira en torno al reconocimiento de ciertas prerrogativas esenciales de la persona humana, algunas de las cuales se abordarán en el presente opúsculo.

La Declaración Universal de Bioética y Derechos Humanos, ${ }^{2}$ celebrada el 19 de octubre de 2005, contempla las cuestiones éticas relacionadas con la medicina, las ciencias de la vida y las tecnologías conexas aplicadas a los seres humanos. Toma en cuenta sus dimensiones sociales, jurídicas y ambientales. En su artículo segundo, establece como uno de sus objetivos "Promover el respeto de la dignidad humana y proteger los derechos humanos, velando por el respeto de la vida de los seres humanos y las libertades fundamentales, de conformidad con el derecho internacional relativo a los derechos humanos". Con una línea similar en el ámbito europeo, el Convenio sobre los Derechos Humanos y la Biomedicina ${ }^{3}$ obliga a los Estados parte a proteger la dignidad y la identidad de todo ser humano, y garantizar - a toda persona, sin discrimina-

\footnotetext{
1 Como enseña Bergel: "El neologismo bioética fue utilizado por primera vez por Rensselaer van Potter, un oncólogo norteamericano, en su recordado libro Bioethics, bridge to the future publicado en 1971, lo que movio a muchos a considerarlo el fundador de esta disciplina". Bergel, Salvador Dario, "Bioética", en Salvador Darío Bergel, Lily Rosa Flah, Marisa Herrera y Eleonora Lamm, Bioética en el Código Civil y Comercial de la Nación, Buenos Aires, Thomson Reuters - La Ley, 2015, p. 1.

2 UnESCO, "Declaración Universal de Bioética y Derechos Humanos", 2005. [Consulta: 17 de septiembre, 2016]. Disponible en: http://portal.unesco.org/es/ev.php-URL_ID=31058\&tURL_DO=DO_TOPIC\&URL_SECTION=201.html

${ }^{3}$ Consejo de Europa, "Convenio sobre los Derechos Humanos y la Biomedicina". [Consulta: 17 de septiembre, 2016]. Disponible en: http://www.colmed2.org.ar/images/code04.pdf
} 
ción- el respeto de su integridad y demás derechos y libertades fundamentales con respecto a las aplicaciones de la biología y de la medicina.

A partir de las nociones expuestas, se presentan ciertas situaciones álgidas para debatir a la sazón de dichos principios: el genoma humano, la clonación, los trasplantes de órganos, la muerte digna, las directivas anticipadas, los derechos sexuales y reproductivos y, de manera más actual, debates en estadio experimental, como el ADN mitocondrial o el trasplante de útero. ¿Cuál es el peso de la libertad personal frente a cada una de estas situaciones? ¿Cuál sería un límite proporcional y razonable al derecho a decidir libremente? ¿Cuáles son los derechos humanos fundamentales implicados en cada una de estas decisiones? ¿Qué rol ocupa el Estado y qué acciones debiera realizar para garantizar el ejercicio pleno de los derechos humanos en el campo biomédico?

A pesar de la cantidad de planteamientos apuntados precedentemente, nos apresuramos a advertir al lector que este trabajo versará sobre los derechos sexuales y reproductivos; particularmente, la relación entre las TRHA y los derechos humanos en el marco de los derechos reproductivos. ${ }^{4}$ A su vez, el objetivo consiste en visibilizar los derechos y principios mínimos sobre los cuáles deberían estructurarse o formularse las legislaciones, políticas y otras acciones en relación con las TRHA. Esto dado el riesgo que traería aparejado la puesta en marcha de un sistema normativo-institucional que ignore un piso mínimo básico y fundamental en materia de derechos humanos, especialmente, ante la posibilidad de incurrirse en responsabilidad internacional.

En relación con la salud sexual y reproductiva, ya en el año 1994, la Conferencia Internacional para la Población y el Desarrollo de la $\mathrm{ONU}^{5}$ señalaba que ésta:

\footnotetext{
${ }^{4}$ Si bien se suele aludir a los derechos sexuales y reproductivos como si fueran lo mismo, cuando no es asi. Por un lado, se encuentran los derechos sexuales y todo lo relativo al derecho a la no reproducción; por el otro, los derechos reproductivos, es decir, el derecho a la procreación. La Corte Interamericana de Derechos Humanos advierte esta diferencia en el caso Artavia Murillo y otros contra Costa Rica, del 28 de noviembre de 2012. Recientemente, el Comité de Derechos Económicos, Sociales y Culturales en su observación general 22, del 2 de mayo de 2016, reiteró: "La salud sexual, tal como se define por la Organización Mundial de la Salud, es "un estado de bienestar físico, emocional, mental y social en relación con la sexualidad". Por otro lado, la salud reproductiva "se refiere a la capacidad de reproducirse y la libertad de tomar decisiones informadas, libres y responsables. También incluye el acceso a una gama de reproducción información de salud, bienes, instalaciones y servicios que permiten a las personas tomar decisiones informadas, libres y responsables sobre su comportamiento reproductivo". Comité de DeReChos Económicos, SOCIALES Y CULTURALES, "The right to sexual and reproductive health (article 12 of the International Covenant on Economic, Social and Cultural Rights)", Colectivo Derecho de Familia. [Consulta: 16 de septiembre, 2016]. Disponible en http://www.colectivoderechofamilia.com/wp-content/uploads/2015/04/Observaci\%C3\%B3n-N-22-DESC_Derechos-sexuales-y-Reproductivos-02-05-2016.pdf

${ }^{5}$ NACIONES UnIDAS, "Informe de la Conferencia Internacional para la Población y el Desarrollo", Egipto, 1994. [Consulta: 17 de septiembre, 2016]. Disponible en: https://www.unfpa.org/sites/default/files/pub-pdf/icpd_spa.pdf
} 
entraña la capacidad de disfrutar de una vida sexual satisfactoria y sin riesgos y de procrear, y la libertad para decidir hacerlo o no hacerlo, cuándo y con qué frecuencia. ${ }^{6}$ Esta última condición lleva implícito el derecho del hombre y la mujer a obtener información y de planificación de la familia de su elección, así como a otros métodos para la regulación de la fecundidad que no estén legalmente prohibidos, y acceso a métodos seguros, eficaces, asequibles y aceptables, el derecho a recibir servicios adecuados de atención de la salud que permitan los embarazos y los partos sin riesgos y den a las parejas las máximas posibilidades de tener hijos sanos. ${ }^{7}$

Tanto en esta Conferencia, como años después en la jurisprudencia de la Corte Interamericana de Derechos Humanos (CIDH), se colocó el foco en que la salud sexual y reproductiva se encuentra fuera del alcance de una gran cantidad de personas de todo el mundo a causa, principalmente, de prácticas sociales discriminatorias. ${ }^{8}$ Por tanto, uno de los principios fundamentales que involucra directamente a los derechos sexuales y reproductivos, desde esta perspectiva obligada, es la no discriminación: su acceso en condiciones de igualdad. Esto implica la libertad de adoptar decisiones relativas a la reproducción y a la constitución familiar sin sufrir discriminación, coacción ni violencia alguna.

En fecha más reciente, el 2 de mayo de 2016, el Comité de Derechos Económicos Sociales y Culturales ha emitido la Observación General 22 dedicada al "Derecho a la Salud Sexual y Reproductiva, artículo 12 del Pacto Internacional de Derechos Económicos, Sociales y Culturales". ${ }^{9}$ En esta oportunidad, el Comité advierte que, debido a las numerosas barreras legales, de procedimiento,

\footnotetext{
${ }^{6}$ El derecho a la autonomía reproductiva está reconocido también en el artículo 16 inciso e) de la Convención para la Eliminación de todas las Formas de Discriminación contra la Mujer, según el cual las mujeres gozan del derecho "a decidir libre y responsablemente el número de sus hijos y el intervalo entre los nacimientos y a tener acceso a la información, la educación y los medios que les permitan ejercer estos derechos". Este derecho es vulnerado cuando se obstaculizan los medios a través de los cuales una mujer puede ejercer el derecho a controlar su fecundidad.

${ }^{7}$ El subrayado nos pertenece.

${ }^{8} \mathrm{La}$ CIDH considera que la prohibición de la fecundación in vitro puede afectar tanto a hombres como a mujeres y les puede producir impactos desproporcionados diferenciados por la existencia de estereotipos y prejuicios en la sociedad CIDH, "Artavia Murrillo y otros c. Costa Rica", [Consulta: 17 de septiembre, 2016]. Disponible en: http://www. corteidh.or.cr/docs/casos/articulos/seriec_257_esp.pdf

${ }^{9}$ Comité de Derechos Económicos, Sociales y Culturales, "The right to sexual and reproductive health (article 12 of the International Covenant on Economic, Social and Cultural Rights)", Colectivo Derecho de Familia. [Consulta: 16 de septiembre, 2016]. Disponible en http://www.colectivoderechofamilia.com/wp-content/uploads/2015/04/Observaci\%C3\%B3n-N-22-DESC_Derechos-sexuales-y-Reproductivos-02-05-2016.pdf
} 
prácticas y sociales, el acceso pleno al derecho a la salud sexual y reproductiva, tales como instalaciones, servicios, bienes e información es seriamente restringido. Añadiendo que el pleno disfrute del derecho a la salud sexual y reproductiva sigue siendo un objetivo lejano para millones de personas, especialmente para las mujeres y las niñas, en todo el mundo. Destaca, asimismo, que hay individuos y grupos de la población que experimentan múltiples formas de discriminación que exacerban la exclusión en la legislación y en la práctica (lesbianas, gays, bisexuales, transgénero e intersexuales y personas con discapacidad). Estas personas tienen mayormente restringido el pleno disfrute del derecho a la salud sexual y reproductiva.

En este contexto, el Comité subraya que la atención integral de la salud sexual y reproductiva contiene cuatro elementos esenciales interrelacionados: disponibilidad, accesibilidad, aceptabilidad y calidad. Por lo que aquí interesa, enfatizamos que "La omisión o negativa para incorporar los avances tecnológicos e innovaciones en la prestación de servicios de salud sexual y reproductiva, tales como medicamentos para el aborto, tecnologías y avances en el tratamiento del $\mathrm{VIH}$ y de reproducción asistida, pone en peligro la calidad de cuidado". ${ }^{10}$

En materia de TRHA, desentrañar, al menos a grandes rasgos, los derechos humanos que se ven comprometidos, resulta un hito fundamental para la construcción de los derechos y principios mínimos sobre los cuales edificar un régimen jurídico institucional acorde con el desarrollo y consolidación de los derechos humanos como perspectiva obligada. Para ello, el punto de partida son los diferentes instrumentos internacionales como regionales de derechos humanos sin perder de vista las voces autorizadas que provienen de la máxima instancia judicial regional en materia de derechos humanos: la cIDH.

Asimismo, como las técnicas de reproducción asistida también han sido objeto de estudio desde la perspectiva obligada de derechos humanos, y desde otro derecho regional como el europeo, también aquí se analizará de manera sintética los avances y desarrollo provenientes del Tribunal Europeo de Derechos Humanos (TEDH). ¿Acaso lo que acontece en el marco de este último tribunal regional también especializado en derechos humanos no es mirado con atención o tiene un fuerte impacto en el desarrollo jurisprudencial de la CIDH? Con sólo compulsar los precedentes del tribunal regional interamericano, fácil se puede concluir el peso que tiene lo que acontece cruzando el Atlántico, en otro tribunal regional especializado en el campo de los derechos humanos.

\footnotetext{
${ }^{10}$ El destacado nos pertenece.
} 


\section{Las técnicas de reproducción humana asistida como vía para el ejercicio y satisfacción de los derechos humanos}

Las TRHA fueron, originariamente, la respuesta frente a un problema médico: la infertilidad. Sin embargo, en la actualidad esta concepción es limitada o restrictiva. Sucede que la reproducción asistida representa el medio para que miles de personas y parejas en el mundo logren alcanzar la paternidad por fuera de la noción de infertilidad, es decir, sin problemas de salud de por medio.

En este contexto, las parejas del mismo sexo apelan a estas técnicas para alcanzar la maternidad o paternidad, al igual que las mujeres que desean ser madres sin tener pareja alguna. Como se puede observar, desde la perspectiva obligada de los derechos humanos, la reproducción asistida implica revisar la noción tradicional de familia en singular, la cual es interpelada por la necesidad de referirse a ellas en plural. Esto constituye una deconstrucción profunda en torno a la protección de la familia a la cual se refiere el artículo 17 de la Convención Americana de Derechos Humanos (СADH).

En otras palabras, la doctrina especializada en la materia hace tiempo que viene planteando y profundizando el siguiente interrogante: ¿Cuál es el fundamento por el cual se produce este viraje que ha sufrido en los últimos años la perspectiva desde donde edificar toda regulación de estas prácticas médicas? Una vez más aparece en escena el principio de igualdad y no discriminación. No es una patología o una "cuestión de salud" la que está presente en toda situación de reproducción asistida, como acontece cuando se trata de una pareja integrada por dos personas del mismo sexo o en casos de mujeres sin pareja. ${ }^{11}$ Aquí es otro el derecho humano comprometido, a saber: el derecho a formar una familia. El alcance del derecho a la vida privada y familiar ostenta una estrecha relación con la autonomía personal y los derechos reproductivos.

Esto sin duda ha desbordado las estructuras jurídicas conocidas hasta el momento, obligando a re pensar y re adecuar los cimientos de un derecho de familia basado en un concepto de familia heterosexual-matrimonial y centrada únicamente en dos fuentes filiales: la filiación por naturaleza y la adoptiva. En este marco, la reproducción asistida coloca en crisis los ordenamientos jurídicos clásicos, fundados en la heteronormatividad y en el binarismo como ejes centrales del derecho filial. De allí la importancia de que las legislaciones más contemporáneas recepten a este tipo de prácticas médicas como un tercer tipo

\footnotetext{
11 Herrera, Marisa y Lamm, Eleonora, "Técnicas de Reproducción Humana Asistida", en Salvador Darío Bergel, Lily Rosa Flah, Marisa Herrera y Eleonora Lamm, Bioética en el Código Civil y Comercial de la Nación, Buenos Aires, Thomson Reuters - La Ley, 2015, p. 315.
} 
filial con sus propias reglas y caracteres como lo hacen en la región países como Brasil, Uruguay y de manera más reciente, integral y sistémica, la Argentina en su nuevo Código Civil y Comercial.

Esta obligada revisión crítica en torno a la noción de familia en singular ha tenido eco en la jurisprudencia de la CIDH en el resonado caso Atala Rifo vs. Chile, ${ }^{12}$ que se retomará en breve para profundizar algunos posibles cimientos de una regulación de las TRHA. En el párrafo 20, la máxima instancia regional en materia de derechos humanos ha expresado de manera clara:

En el marco de las sociedades contemporáneas se dan cambios sociales, culturales e institucionales encaminados a desarrollos más incluyentes de todas las opciones de vida de sus ciudadanos, lo cual se evidencia en la aceptación social de parejas interraciales, las madres o padres solteros o las parejas divorciadas, las cuales en otros momentos no habían sido aceptadas por la sociedad. En este sentido, el Derecho y los Estados deben ayudar al avance social, de lo contrario se corre el grave riesgo de legitimar y consolidar distintas formas de discriminación violatorias de los derechos humanos.

Desde una mirada más actual y comprometida con la idiosincrasia regional, se resalta:

El modelo latinoamericano enfatiza un «bios» humano y un "ethos» comunitario. Esta es la razón por la cual la bioética es hoy más un movimiento político o de reforma social que una disciplina académica restringida al dominio de la atención de la salud. En la bioética latinoamericana los principios de solidaridad y justicia juegan el papel central [...] las políticas de salud latinoamericana abrazan el acceso universal al cuidado de la salud y ponen el acento en la justicia distributiva y la equidad en la asignación de recursos para la salud. ${ }^{13}$

Beneficiarse del progreso científico es otro derecho humano directamente involucrado en las TRHA. El desarrollo, avance y perfeccionamiento de la ciencia produce herramientas y conocimientos para mejorar la calidad de vida de las personas. Ahora bien, establecer principios rectores para el uso de estos avan-

\footnotetext{
${ }^{12}$ CIDH, "Atala Riffo y Niñas vs. Chile". [Consulta: 17 de septiembre, 2016]. Disponible en: http://corteidh.or.cr/docs/ casos/articulos/seriec_239_esp.pdf

${ }^{13}$ MAINETII, José, "Desarrollo de la bioética en América Latina", 15/09/2016, MJ-DOC-10291-AR | MJD10291.
} 
ces es la vía adecuada para neutralizar las consecuencias negativas de algunos logros científicos y tecnológicos. ${ }^{14}$ La bioética, como disciplina de la ética, intenta compatibilizar estos avances con el respeto por el ser humano y sus derechos humanos fundamentales.

La realidad cotidiana da cuenta de numerosas parejas y personas que han podido alcanzar la maternidad/paternidad gracias al desarrollo de la ciencia. Además, ha permitido mejorar y aumentar la calidad de la salud. Por ejemplo, la técnica del diagnóstico genético preimplantacional (DGP) detecta anomalías en el embrión para evitar que se transmitan a la descendencia o a embriones que se sabe que no tienen capacidad para desarrollarse. 0 , de manera más actual, el mencionado trasplante de útero que habilita a personas que no pueden gestar para hacerlo. ${ }^{15}$

Voces autorizadas respaldan e impulsan esta postura encaminada a beneficiarse de la ciencia, sin que ello se encuentre supeditado a un impedimento de salud. La Asamblea General de las Naciones Unidas, en su Declaración sobre la utilización del progreso científico y tecnológico en el interés de la paz y el beneficio de la humanidad, ${ }^{16}$ ha establecido: "Los Estados deben adoptar las medidas necesarias para que la utilización de los logros de la ciencia y la tecnología contribuya a la realización más plena posible de los derechos humanos y las libertades fundamentales sin discriminación alguna por motivos de raza, sexo, idioma o creencias religiosas".

\section{Una voz autorizada: la Corte Interamericana de Derechos Humanos}

América Latina cuenta con un tribunal regional especializado en derechos humanos: la Corte Interamericana de Derechos Humanos (СіDH). Desde sus albores, en 1979, se dedicó a emitir opiniones consultivas. Su rol jurisdiccional inició recién en 1987. En su primera etapa contenciosa, se abocó a delitos de lesa humanidad. La responsabilidad internacional de los Estados parte se centraba en

\footnotetext{
${ }^{14}$ NaCIONES UNIDAS, "Declaración sobre la utilización del progreso científico y tecnológico en interés de la paz y beneficio de la humanidad", 1975. [Consulta: 17 de septiembre, 2016]. Disponible en: http://www.ohchr.org/SP/ Professionallnterest/Pages/ScientificAndTechnologicalProgress.aspx

${ }^{15}$ Chávez, Valeria, "Por primera vez se hará un trasplante de útero en Argentina", Infobae. [Consulta: 17 de septiembre, 2016]. Disponible en: http://www.infobae.com/2016/03/11/1796228-por-primera-vez-se-hara-un-trasplanteutero-argentina/

${ }^{16}$ NACIONES UNIDAS, "Declaración sobre la utilización del progreso científico y tecnológico en interés de la paz y beneficio de la humanidad", 1975. [Consulta: 17 de septiembre, 2016]. Disponible en: http://www.ohchr.org/SP/ Professionallnterest/Pages/ScientificAndTechnologicalProgress.aspx
} 
el derecho penal humanitario, al encontrarse comprometidas fuertes restricciones a la vida, la libertad y la dignidad. Muchos años después, la ciDH comenzó a inmiscuirse en el campo de las relaciones de familia, brindando pautas de interpretación en variados y relevantes conflictos.

Las TRHA no han estado fuera del debate contemporáneo regional de los derechos humanos. En este sentido, el presidente de este órgano en el período 2010-2014, el peruano García Sayán, destacó:

La democratización de las conciencias en América Latina hace que se haya generalizado y extendido la percepción de los derechos, llegando a la Corte algunas materias que hace algunos años hubiese sido impensado que llegaran: derechos a la orientación sexual, métodos científicos de fertilización, asuntos de acceso a la información y otros, lo que da cuenta de que cada vez hay más gente que sabe que si sus derechos no fueron satisfechos en el fuero interno, existe una instancia internacional. ${ }^{17}$

Este organismo tiene gran peso para los Estados de la región que han ratificado la Convención Americana de Derechos Humanos (CADH) en el campo de las TRHA. Los aportes concretos de esta voz autorizada en derechos humanos es lo que se destaca a continuación a la luz de tres casos jurisprudenciales. Las TRHA tienen la virtud, entre otras, de revisar de manera crítica el derecho filial y, a la par, ampliar el ámbito de aplicación subjetivo de estas técnicas, o sea, quién o quiénes pueden acceder a ellas.

En la actualidad se ha ampliado considerablemente la noción de familia. Se ha reafirmado el uso del vocablo "familias", en vez del tradicional en singular. Una de las sentencias de mayor impacto en el campo de las relaciones de familia y la reproducción asistida es el caso Atala Riffo y otros contra Chile, del 24 de febrero de $2012 .{ }^{18}$ Se trata del caso de una jueza chilena lesbiana a quien le quitaron la tuición de sus hijas por su orientación sexual.

Esta es la primera vez que la CIDH se ocupa de dilucidar las siguientes cuestiones: 1) los alcances del derecho a la igualdad y a la no discriminación; 2) la orientación sexual como categoría protegida por el artículo 1.1 de la Convención Americana; 3) si en el caso existió- una diferencia de trato basada en la

\footnotetext{
17 "Diego García Sayán habla sobre la Corte IDH en entrevista con el Mercurio Legal", Universidad de Chile. [Consulta: 16 de septiembre, 2016]. Disponible en: http://www.cdh.uchile.cl/noticias/detalle.tpl?id=20130722154614 ${ }^{18} \mathrm{CIDH}$, "Atala Riffo y Niñas vs. Chile". [Consulta: 17 de septiembre, 2016]. Disponible en: http://corteidh.or.cr/docs/ casos/articulos/seriec_239_esp.pdf
} 
orientación sexual, y 4) si dicha diferencia de trato constituyó discriminación. ${ }^{19}$ Aquí la máxima instancia judicial regional analiza la cuestión en dos planos: en lo general, es decir, respecto a la orientación sexual como "categoría sospechosa"; y en particular, en lo atinente al "interés superior del niño". Con relación al primero, se asevera que "los tratados de derechos humanos son instrumentos vivos, cuya interpretación tiene que acompañar la evolución de los tiempos y las condiciones de vida actuales" (párrafo 83). Sobre esa base, se responde que cuando la CADH alude a "cualquier condición social", se incluye a la orientación sexual.

Por ende, se afirma de manera terminante que el principio de no discriminación fundado en la orientación sexual de las personas constituye una categoría sospechosa y, por ende, se debe aplicar "un escrutinio estricto" (párrafo 73). ${ }^{20}$ Con respecto al segundo, la CIDH considera que "El interés superior del niño no puede ser utilizado para amparar la discriminación en contra de la madre o el padre por la orientación sexual de cualquiera de ellos. De este modo, el juzgador no puede tomar en consideración esta condición social como elemento para decidir sobre una tuición o custodia" (párrafo 110). Por ende, "no son admisibles las consideraciones basadas en estereotipos por la orientación sexual, es decir, pre-concepciones de los atributos, conductas o características poseídas por las personas homosexuales o el impacto que estos presuntamente puedan tener en las niñas y los niños".

En este contexto jurisprudencial convencional, se asevera de manera elocuente que "en la Convención Americana no se encuentra determinado un concepto cerrado de familia, ni mucho menos se protege sólo un modelo "tradicional' de la misma”. Y agrega, "el Tribunal reitera que el concepto de vida familiar no está reducido únicamente al matrimonio y debe abarcar otros lazos familiares de hecho donde las partes tienen vida en común por fuera del matrimonio" (párrafo 142). De ello se concluye la mirada benigna hacia las TRHA como un modo para ejercer el derecho a formar una familia. Además, se asume como la única vía para muchos en este marco de reconocimiento a diversos modelos familiares.

El segundo precedente del corpus iuris convencional regional de las TRHA es el caso Fornerón y otro contra Argentina del 27 de abril de 2012. ${ }^{21}$ Si bien aquí

\footnotetext{
19 Kemelmajer de Carluccl, Aida y Herrera, Marisa, "Una voz autorizada del ámbito regional manda no discriminar en razón de la orientación sexual", La Ley, 2012, p. 1254.

${ }^{20}$ Se agrega que "la presunta falta de un consenso al interior de algunos paises sobre el respeto pleno por los derechos de las minorias sexuales no puede ser considerado como un argumento válido para negarles o restringirles sus derechos humanos o para perpetuar y reproducir la discriminación histórica y estructural que estas minorías han sufrido" (párrafo 92).

${ }^{21}$ CIDH, "Fornerón e hija vs. Argentina". [Consulta: 17 de septiembre, 2016]. Disponible en: http://corteidh.or.cr/docs/ casos/articulos/seriec_242_esp.pdf
} 
el eje central gira en torno a otro tipo filial como el adoptivo, lo cierto es que de manera general se amplía aún más la noción de familia y su protección a la luz del artículo 17 de la cADH. Éste reconoce y fortalece la familia monoparental. Las TRHA constituyen otro modo de monoparentalidad originaria, en contraposición con la cantidad de situaciones de monoparentalidad derivada, es decir, devenida de ciertos acontecimientos, como el fallecimiento de uno de los progenitores o la ruptura de la pareja y abandono de uno de ellos del núcleo familiar.

Por el contrario, la monoparentalidad originaria acontece cuando un niño nace en el marco de una familia comandada por una persona sola, como se deriva de las situaciones de adopción unilateral, pero ampliando los supuestos de manera considerable por incidencia de las TRHA. Tratándose de reproducción asistida, las situaciones de monoparentalidad originaria pueden ser varias: a) por la decisión de una mujer de tener un hijo apelando a la donación de esperma -aportando o no su propio material genético femenino-; b) en aquellos países que admiten la figura de la gestación por sustitución, habilitando que un hombre solo pueda ser padre y c) a través de otra figura controvertida, como la fertilización post mortem, es decir, permitir que una persona siga adelante con el proyecto parental ideado con su pareja, quien fallece durante el tratamiento o incluso antes (los familiares solicitan la extracción post mortem del material genético para una futura inseminación).

En el párrafo 98 del caso Fornerón, la máxima instancia judicial regional ha resaltado: "no hay nada que indique que las familias monoparentales no puedan brindar cuidado, sustento y cariño a los niños. La realidad demuestra cotidianamente que no en toda familia existe una figura materna o una paterna, sin que ello obste a que ésta pueda brindar el bienestar necesario para el desarrollo de niños y niñas”. ¿Cómo incide o en qué se relaciona esta afirmación en el campo de las TRHA? ¿Acaso una legislación estadual podría prohibir o limitar los diferentes modos de acceso a la monoparentalidad originaria que permite el uso de las TRHA?

Además de los supuestos sintetizados de monoparentalidad originaria derivada de las TRHA, de manera general, también cabe resaltar cómo incide la concepción amplia de familias en plural que se deriva de la jurisprudencia convencional, en particular, del reconocimiento expreso de las familias monoparentales.

Tomando como ejemplo la regulación argentina, una de las más avanzadas y modernas en la región en reproducción asistida, se destaca la ley 26.862 de acceso integral a las técnicas de reproducción asistida, sancionada en el 2013. Esta herramienta normativa se dedica a la cobertura médica de estas prácticas 
médicas. El artículo 7, referido a los "Beneficiarios" dispone que "Tiene derecho a acceder a los procedimientos y técnicas de reproducción médicamente asistida, toda persona mayor de edad que, de plena conformidad con lo previsto en la ley 26.529, de derechos del paciente en su relación con los profesionales e instituciones de la salud, haya explicitado su consentimiento informado". De esta manera, la regulación estadual citada permite que toda persona (esté o no en pareja) acceda a las TRHA para ver satisfecho su derecho a formar una familia.

La CIDH ha tenido la oportunidad de profundizar sobre las TRHA en el resonado caso Artavia Murillo y otros contra Costa Rica, del 28 de noviembre de $2012^{22}$ reafirmado en la sentencia en el proceso de seguimiento del 26 de febrero 2016. ${ }^{23}$ Se trata de un grupo de parejas que rechazan la prohibición de la fertilización in vitro (FIV), tras la decisión de la Sala Constitucional de la Corte Suprema de Justicia de Costa Rica (15 de marzo del 2000) en ese sentido. Dicho grupo argumentó que esta técnica de reproducción asistida de alta complejidad implicaba la manipulación de personas. De allí su necesidad de declarar la inconstitucionalidad de algunas disposiciones del decreto ejecutivo 24029-S del 3 de febrero de 1995 que regulaba las TRHA. Los demandantes entendieron que la prohibición efectuada por el Estado de Costa Rica constituía una injerencia arbitraria en los derechos a la vida privada, a la vida privada familiar (artículo 11 de la Convención Americana) y el derecho a conformar una familia (artículo 17), amén de la consecuente violación al derecho de igualdad (artículo 24).

En este marco, la CIDH se pronunció por primera vez sobre uno de los procedimientos de reproducción asistida más sensibles desde el punto de vista ético: la fecundación in vitro. En este tratamiento la unión entre el óvulo y el esperma acontece fuera del cuerpo de la persona. ${ }^{24}$ Básicamente, aquí la interpretación ha girado en torno a la noción de "concepción" que recepta el artículo 4.1 de la $\mathrm{CADH}$, referido al derecho a la vida. En otras palabras, reflexiona si el embrión se encuentra protegido por la noción de persona a la luz de lo dispuesto en dicha normativa. Aquí, la ciDH concluye, en el párrafo 264, que: “el embrión in vitro no puede ser entendido como persona a los efectos del artículo 4.1 de la Con-

\footnotetext{
${ }^{22}$ CIDH, "Artavia Murrillo y otros vs. Costa Rica". [Consulta: 17 de septiembre, 2016]. Disponible en: http://www.corteidh.or.cr/docs/casos/articulos/seriec_257_esp.pdf

${ }^{23}$ CIDH, "Artavia Murrillo y otros vs. Costa Rica". [Consulta: 17 de septiembre, 2016]. Disponible en: http://www.corteidh.or.cr/docs/casos/articulos/seriec_257_esp.pdf

${ }^{24}$ Aqui se alude en general a la noción de "persona" y no de "mujer", de conformidad con aquellas legislaciones, como la argentina, en que se permite el cambio de identidad de género fundado en la "identidad autopercibida", sin necesidad de tener que someterse a operación quirúrgica alguna (artículo 2, ley 26.743). En este contexto, un hombre trans podría quedar embarazado y este niño sería gestado por un hombre y no por mujer.
} 
vención Americana" y que "la concepción en el sentido del artículo 4.1 tiene lugar desde el momento en que el embrión se implanta en el útero".

Para arribar a esta conclusión, la máxima instancia judicial regional esgrime varias afirmaciones esenciales para estructurar los cimientos básicos sobre los cuales edificar una regulación estadual en torno a las TRHA. A la luz de la obligada perspectiva convencional-constitucional, donde los derechos humanos ocupan un lugar central en la agenda legal-jurídica, se destacan los siguientes factores.

El derecho a la vida privada. Sobre la base de una interpretación amplia de libertad, en el sentido de hacer y no hacer lo que está lícitamente permitido, la CIDH reafirma "el derecho de toda persona de organizar, con arreglo a la ley, su vida individual y social conforme a sus propias opciones y convicciones. La libertad, definida así, es un derecho humano básico, propio de los atributos de la persona, que se proyecta en toda la Convención Americana” (párrafo 142). En esta línea, el párrafo 143 expresa que "la maternidad forma parte esencial del libre desarrollo de la personalidad de las mujeres. Teniendo en cuenta todo lo anterior, la Corte considera que la decisión de ser o no madre o padre es parte del derecho a la vida privada e incluye, en el presente caso, la decisión de ser madre o padre en el sentido genético o biológico". Por otra parte, desde la obligada mirada sistémica de la cual se deriva la interdependencia de los derechos humanos, la cIDH reconoce, en el párrafo 146, que el derecho a la vida privada se vincula de manera directa con "i) la autonomía reproductiva, y ii) el acceso a servicios de salud reproductiva, lo cual involucra el derecho de acceder a la tecnología médica necesaria para ejercer ese derecho".

El derecho a la salud y en particular, a la salud reproductiva. Según la Organización Panamericana de la Salud, "transferir a una mujer todos los embriones producidos en cada ciclo de un tratamiento de [FIV], incluso aquellos embriones que tienen defectos, puede poner en peligro el derecho a la vida de la mujer e incluso ocasionar la realización de un aborto terapéutico lo que a su vez afecta negativamente el goce del derecho a la salud y de otros derechos humanos relacionados que han sido acordados por los Estados de la ops".

En esta misma línea, la CIDH considera que "una de las injerencias directas en la vida privada se relaciona con el hecho de que la decisión de la Sala Constitucional impidió que fueran las parejas quienes decidieran sobre si deseaban o no someterse en Costa Rica a este tratamiento para tener hijos. La injerencia se hace más evidente si se tiene en cuenta que la fiv es, en la mayoría de los casos, la técnica a la que recurren las personas o parejas después de haber intentado otros tratamientos para enfrentar la infertilidad [...] o, en otras cir- 
cunstancias, es la única opción con la que cuenta la persona para poder tener hijos biológicos".

El derecho a formar una familia. Se asevera que "la decisión de tener hijos biológicos a través del acceso a técnicas de reproducción asistida forma parte del ámbito de los derechos a la integridad personal, libertad personal y a la vida privada y familiar. Además, la forma como se construye dicha decisión es parte de la autonomía y de la identidad de una persona tanto en su dimensión individual como de pareja". Con esto se reafirma que las TRHA "se ofrecen como un medio para ejercer el legítimo ejercicio del derecho a la reproducción humana, que, aunque no está expresamente reconocido en [la] Constitución Política, se deriva del derecho a la libertad y la autodeterminación, el derecho a la intimidad personal y familiar y a la libertad para fundar una familia”.

El derecho a beneficiarse del desarrollo y progreso científico. Se afirma que "Del derecho de acceso al más alto y efectivo progreso científico para el ejercicio de la autonomía reproductiva y la posibilidad de formar una familia se deriva el derecho a acceder a los mejores servicios de salud en técnicas de asistencia reproductiva, y, en consecuencia, la prohibición de restricciones desproporcionadas e innecesarias de iure o de facto para ejercer las decisiones reproductivas que correspondan en cada persona".

El derecho a la no discriminación. La CIDH profundiza sobre la noción de discriminación inversa. En este contexto diferencia:

- La discriminación indirecta en relación con la discapacidad. Alega que "la infertilidad es una limitación funcional reconocida como una enfermedad y que las personas con infertilidad en Costa Rica, al enfrentar las barreras generadas por la decisión de la Sala Constitucional, debían considerarse protegidas por los derechos de las personas con discapacidad. En ello se incluye el derecho de acceder a las técnicas necesarias para resolver problemas de salud reproductiva. Dicha condición demanda una atención especial para que se desarrolle la autonomía reproductiva" (párrafo 293).

- La discriminación indirecta en relación al género. Destaca que la infertilidad tiene un impacto diferente -y mayor- en las mujeres, por ello "estos estereotipos de género son incompatibles con el derecho internacional de los derechos humanos y se deben tomar medidas para erradicarlos. El Tribunal no está validando dichos estereotipos y tan sólo los reconoce y visibiliza para precisar el impacto desproporcionado de la interferencia generada por la sentencia de la Sala Constitucional”. 
- Discriminación indirecta en relación con la situación económica. Es el impacto de la prohibición de la fecundación in vitro más severo o desproporcionado en parejas infértiles que carecen de recursos económicos para acceder a estas costosas prácticas médicas.

Esta apretada síntesis es elocuente para demostrar que la cIDH no sólo está a favor del uso de las TRHA, sino, además, lo hace de un modo absolutamente plural. Para ello, entiende necesario que lo sea desde una perspectiva laica alejada de toda connotación religiosa. Esto se explicita cuando afirma: "Hay concepciones que ven en los óvulos fecundados una vida humana plena. Algunos de estos planteamientos pueden ser asociados a quienes confieren ciertos atributos metafísicos a los embriones. Estas posiciones no pueden justificar que se otorgue prevalencia a cierto tipo de literatura científica al momento de interpretar el alcance del derecho a la vida consagrado en la Convención Americana, pues ello implicaría imponer un tipo de creencias específicas a otras personas que no las comparten”.

\section{Diálogo transatlántico ${ }^{25}$}

El Tribunal Europeo de Derechos humanos (TEDH), creado en el año 1954 y constituido finalmente en el año 1959, es el órgano encargado de supervisar que los Estados parte cumplan las obligaciones que surgen de la Convención Europea de Derechos Humanos. Esta última entró en vigor en 1953.

Como efecto directo de las violaciones atroces de derechos humanos ocurridas en el marco de la Segunda Guerra Mundial, al igual que en el caso de su corte congénere americana, los primeros años del TEDH estuvieron signados por casos que comprometían delitos de lesa humanidad. Tal es así que el Convenio Europeo, en su versión primigenia, no incluía una lista extensa de derechos, sino una bastante genérica y estrecha. Sin embargo, se fue extendiendo y en-

\footnotetext{
${ }^{25}$ Se usa este vocablo en referencia a un trabajo elaborado en conjunto por la Corte Interamericana y el Tribunal Europeo de Derechos Humanos, en donde se expresa: "La importancia de esta cooperación debe ser reconocida, dada la similitud de los derechos y libertades protegidos por los respectivos tratados fundacionales de ambas cortes, así como la existencia en ambos sistemas de criterios de admisibilidad y principios de interpretación muy parecidos. Además, la creciente convergencia en las temáticas planteadas ante ambas jurisdicciones confiere una nueva y mayor relevancia a sus respectivas Jurisprudencias [...] Aparte de la importancia que tienen en si mismas, algunas de estas decisiones sirven para ilustrar cómo ambas jurisdicciones toman en consideración el enfoque de la otra en materia de protección de los derechos humanos". TEDH y CIDH, "Diálogo Transatlántico: Selección de Jurisprudencia del Tribunal Europeo y la Corte Interamericana de Derechos Humanos", Wolf Legal Publishers, 2015. [Consulta: 20 de septiembre, 2016]. Disponible en: http://www.echr.coe.int/Documents/Dialogue_Across_Atlantic_SPA.pdf
} 
grosando a partir de la ratificación de protocolos adicionales al Convenio. ${ }^{26}$

Con el transcurso del tiempo, y más prolíferamente en los últimos quince años, el TEDH ha tenido que resolver muchos conflictos relacionados específicamente con las nuevas biotecnologías. En particular, en materia de técnicas de reproducción humana asistida ${ }^{27}$ ha tenido que evaluar distintas normativas estaduales a la luz de los artículos 8 y 14 del Convenio Europeo de Derechos Humanos.

Resulta conveniente recordar el texto de ambos artículos:

Artículo 8. Derecho al respeto a la vida privada y familiar. 1. Toda persona tiene derecho al respeto de su vida privada y familiar, de su domicilio y de su correspondencia. 2. No podrá haber injerencia de la autoridad pública en el ejercicio de este derecho sino en tanto en cuanto esta injerencia esté prevista por la ley y constituya una medida que, en una sociedad democrática, sea necesaria para la seguridad nacional, la seguridad pública, el bienestar económico del país, la defensa del orden y la prevención de las infracciones penales, la protección de la salud o de la moral, o la protección de los derechos y las libertades de los demás.

Art. 14: Prohibición de discriminación. El goce de los derechos y libertades reconocidos en el presente Convenio ha de ser asegurado sin distinción alguna, especialmente por razones de sexo, raza, color, lengua, religión, opiniones políticas u otras, origen nacional o social, pertenencia a una minoría nacional, fortuna, nacimiento o cualquier otra situación.

En este marco genérico, conviene detenernos, brevemente, en tres sentencias que, si bien no refieren a la temática que nos ocupa en esta oportunidad, resultan relevantes porque dejan en claro que en materia relaciones paterno-materno filiales -sean producto del uso de las TRHA, o por filiación biológica

\footnotetext{
${ }^{26}$ Como el protocolo adicional al Convenio para la Protección de los Derechos Humanos y de las Libertades Fundamentales (1952), Protocolo 4 (1963), 6 (1983), 7 (1984), 12 (2000) y 13 (2002). Respecto al procedimiento de las denuncias y los legitimados para plantearla el Protocolo 11 destaca: "A partir de 1998 la legitimación para recurrir frente a los Estados parte se extiende (aparte de a los mismos Estados, que muy raramente han utilizado esta posibilidad) a todas las personas (individuos u organizaciones de tipo no gubernamental) sujetas a su jurisdicción, que tendrán acceso asi en forma directa al Tribunal: el Protocolo 11 suprimió la Comisión Europea de Derechos Humanos, que actuaba hasta el momento como filtro respecto de las demandas individuales. Asi y todo, esta legitimación se refiere únicamente a quienes se consideren víctimas de una violación de sus derechos, excluyéndose la posibilidad de una actio popularis ante el Tribunal. El tribunal ha considerado la noción de víctima como uno de los denominados "conceptos autónomos", que han de definirse por la propia jurisprudencia. Por otro lado, la legitimación pasiva corresponde en exclusiva a los Estados; no caben demandas frente a actuaciones de particulares". López GuerRA, LuIS, "El Sistema Europeo de Protección de Derechos Humanos". [Consulta: 20 de septiembre, 2016]. Disponible en: https:// www.upf.edu/dhes-alfa/materiales/res/pmdh_pdf/PMDH_Manual.165-186.pdf

${ }^{27}$ En esta oportunidad, dado que tenemos como objetivo la construcción de un diálogo o análisis en espejo entre las decisiones de la Corte Interamericana de Derechos Humanos y el Tribunal Europeo de Derechos Humanos en materia de TRHA, no analizaremos las sentencias del TEDH relativas a los casos de gestación por sustitución.
} 
o adoptiva- los Estados no deben introducir en sus regulaciones distinciones basadas en la orientación sexual de los progenitores o pretensos progenitores.

La primera vez que el TEDH juzgó que una diferencia de trato basada en la orientación sexual del individuo violaba la prohibición de trato discriminatorio del artículo 14 del Convenio, en relación con el derecho al respeto de la vida privada y familiar, fue en el caso Salgueiro da Silva Mouta $v$ s. Portugal, del 21 de diciembre de $1999 .{ }^{28}$ Se trataba de un caso muy similar al caso Atala Riffo, resuelto por la Corte Interamericana años después. Un hombre, tras divorciarse de su mujer e iniciar una relación afectiva con otro hombre, fue privado del cuidado de su hija por razón de su orientación sexual. El TEDH consideró que la decisión de la justicia de Lisboa constituyó un acto discriminatorio basado en la orientación sexual del padre de la niña, categoría incluida y protegida por el artículo 14 del Convenio Europeo. ${ }^{29}$

Años después, el Tribunal de Estrasburgo dio un paso más en el reconocimiento de familias diversas. Resolvió un conflicto suscitado frente la negativa del Estado francés a conceder una adopción unipersonal a una mujer homosexual. Se trata del caso E. B. vs. France ( $N^{\circ}$ 435466/02) del 22 de enero 2008. ${ }^{30}$ La legislación francesa prevé la posibilidad de que una persona sola adopte a un niño. No obstante, ante la solicitud de una adopción unipersonal por parte de una mujer francesa homosexual, las autoridades administrativas y judiciales de Francia consideraron que no estaban dadas las condiciones para una adopción porque: a) falta de la figura paterna, importante a la luz del interés superior del niño y b) la pareja de la demandante había mostrado ambigüedad frente al compromiso que implica la adopción. Llegado el caso al TEDH, afirmó que, por tratarse de una adopción individual, en la que siempre falta alguna de las figuras (materna o paterna) la denegatoria de las autoridades francesas configuró un supuesto de discriminación por orientación sexual (artículo 14 de la Convención) que implicó una violación al derecho a la vida familiar (artículo 8). ${ }^{31}$

El 19 de febrero de 2013, el TEDH resolvió un segundo caso en materia de adopción y orientación sexual, $\mathrm{X}$ and Others vs. Austria, ${ }^{32}$ esta vez contra el Es-

\footnotetext{
${ }^{28}$ Tribunal Europeo de Derechos Humanos, "Salgueiro Da Silva Mouta vs. Portugal", 1999. [Consulta: 20 de septiembre, 2016]. Disponible en http://www.gddc.pt/direitos-humanos/portugal-dh/acordaos/traducoes/Trad_033290_96.pdf

${ }^{29}$ Manzano Barragán, Iván, "La jurisprudencia del Tribunal Europeo de Derechos Humanos sobre orientación sexual e identidad de género", Revista Española de Derecho Internacional, vol. 46, No. 2, Madrid, julio-diciembre 2012.

${ }^{30}$ Tribunal Europeo de Derechos Humanos, "E. B vs. France". [Consulta: 20 de septiembre, 2016]. Disponible en: http:// www.1 1 cor.com/1315/?form_1155.replyids=1129

${ }^{31}$ En esta sentencia, el TEDH, revierte su postura contraria anterior. TRIBUnAl Europeo de Derechos Humanos, "Frette vs. France (36515/97)", 2002. Disponible en: http://www.equalrightstrust.org/ertdocumentbank/frette\%20v\%20france.pdf

32 Tribunal Europeo de Derechos Humanos, 19/02/2013, "X and Others vs. Austria", La Ley, 2013.
} 
tado de Austria, por restringir el acceso a la adopción de integración del hijo del conviviente en parejas del mismo sexo no casadas. En esta oportunidad, los jueces de Estrasburgo sostuvieron, categóricamente, que la diferencia de trato entre parejas homosexuales y heterosexuales no casadas, en las cuales uno de sus integrantes desea adoptar al hijo del otro, viola la prohibición de discriminación y el derecho a la vida familiar. Esto dado que se fundamenta en la orientación sexual, y no existen razones convincentes para que sea una distinción necesaria para la protección de la familia o de los intereses de las personas menores de edad.

El 7 de marzo de 2006, el Tribunal Europeo resolvió un caso, Evans vs. Reino Unido de Gran Bretaña e Irlanda del Norte, de sumo interés en materia de técnicas de reproducción humana asistida. Una pareja inició un tratamiento en una clínica especializada en reproducción médica asistida. En una de las primeras consultas en la clínica, le informaron a la pareja que la joven padecía de graves tumores precancerosos en ambos ovarios y que debía someterse a una ovariotomía bilateral. Se les indicó que, como los tumores se desarrollaban lentamente, era posible obtener algunos óvulos antes de la ablación para su fecundación in vitro, pero que la obtención debía efectuarse cuanto antes.

Ante este escenario, la mujer consultó si sería posible congelar sus óvulos no fecundados, es decir, criopreservar los gametos en forma separada. Dado que recibió una negativa a su consulta, decidieron dar inicio a la fecundación in vitro. Cada uno firmó un formulario expresando su consentimiento al tratamiento. Se les informó que, conforme las disposiciones de la Ley de 1990 de fecundación y embriología humanas, cada uno de ellos tendría la posibilidad de retirar su consentimiento en todo momento, mientras los embriones no hubiesen sido implantados en el útero de la mujer.

El 12 de noviembre de 2001, la pareja acudió a la clínica y se obtuvieron y fecundaron once óvulos. Se crearon así y conservaron seis embriones. El 26 de noviembre, la mujer sufrió la ablación de sus dos ovarios y se le informó que debía esperar dos años antes de tratar de implantar un embrión en su útero. En mayo de 2002, la relación de pareja finalizó. El 4 de julio de 2002, el señor notificó por escrito a la clínica que la pareja se había separado y que los embriones debían ser destruidos. Es decir, retiró su consentimiento para la utilización posterior de los embriones.

La mujer acudió al centro de salud solicitando la transferencia de los embriones pese a la revocación del consentimiento de su ex pareja y, ante la negativa de la clínica, se presentó ante la justicia pidiendo la autorización, máxime, alega, cuando es la única oportunidad que tiene para tener un hijo con su material genético, puesto que había sufrido una ablación de ovarios. La justicia, 
en todas las instancias, confirmó la negativa a transferir los embriones, considerando que el objeto de la Ley británica de 1990 era claramente no autorizar la implantación del embrión a menos que las dos partes hubiesen mantenido su consentimiento a lo largo de todo el proceso.

En estas condiciones, el caso llegó al Tribunal de Estrasburgo. La mujer alegó que las disposiciones aplicables de la Ley de 1990, que exigen el consentimiento de su ex compañero, violan sus derechos en virtud de los artículos 8 y 14, así como el derecho de los embriones a la vida, en virtud del artículo 2 del Convenio. Sobre la alegada violación del artículo 2 del Convenio, respecto de los embriones criopreservados, el Tribunal recordó:

Sin embargo, que en la Sentencia Vo contra Francia [...] consideró que, a falta de un consenso europeo sobre la definición científica y jurídica del inicio de la vida, el punto de partida del derecho a la vida dependía del margen de apreciación de los Estados que el Tribunal tiende a considerar se les debe reconocer en este ámbito. Ahora bien, tal y como precisaron los tribunales internos en el presente caso, la legislación británica no reconoce al embrión la calidad de sujeto de derecho autónomo ni le autoriza a prevalerse -por persona interpuesta- del derecho a la vida garantizado por el artículo 2. En consecuencia, no ha habido en este caso violación de esta disposición.

En relación con el planteamiento de una violación al artículo 8 por el Estado británico al sancionar la Ley de 1990, el Tribunal utiliza su conocida "doctrina" del margen de apreciación de los Estados. En este sentido, le concedió un amplio margen de apreciación:

El Tribunal considera que, insertando en la Ley de 1990 una disposición clara basada en consideraciones de principio, que reconoce a cada una de las personas afectadas por un tratamiento de fiv la libertad de retractarse hasta el momento de la implantación del embrión, que fue explicada a los participantes en el tratamiento en cuestión y que figuraba explícitamente en los formularios que éstos firmaron, el Reino Unido no ha excedido el margen de apreciación de que dispone ni ha roto el equilibrio exigido por el artículo 8 del Convenio.

Por último, el Tribunal considera que la denuncia de violación del artículo 14 en relación con el artículo 8 no puede prosperar, pues los motivos que le han 
llevado a concluir con la no violación del artículo 8 constituyen también una justificación objetiva y razonable a efectos del artículo 14 .

El 28 de agosto de 2012 el TEDH resolvió otro caso referido a reproducción asistida: Costa y Pavan $v$ s. Italia. ${ }^{33}$ Un matrimonio, tras el nacimiento de su primera hija, año 2006, descubrieron que eran portadores sanos de fibrosis quística y que habían transmitido esta enfermedad a su hija. En febrero de 2010, estando la mujer nuevamente embarazada, decidieron efectuar un diagnóstico prenatal. De éste resultó que el feto también estaba afectado por la mucoviscidosis. Ante esta situación de suma angustia, decidieron realizar una interrupción médica del embarazo. Luego, pese a no tener problemas de infertilidad, intentaron acceder a la maternidad/paternidad por vía del uso de las TRHA. Acudieron previamente a un diagnóstico genético preimplantacional (DGP) ${ }^{34}$ que les permitiera tener descendencia libre de la enfermedad. Sin embargo, en virtud de los términos de la ley italiana 40, del 19 de febrero de 2004, las TRHA sólo están disponibles para las parejas estériles o infértiles y, asimismo, el DGP está prohibido para cualquier clase de personas.

El matrimonio llevó el caso al Tribunal de Estrasburgo. Denunciaron violación al artículo 8 del Convenio, vida privada y familiar, en la medida en que la única vía para ellos de tener hijos que no estén afectados por su enfermedad es fecundarlos de una manera natural y proceder a una interrupción médica del embarazo cada vez que un diagnóstico prenatal muestre que el feto está afectado.

En este sentido, el Tribunal constató que, en la legislación italiana, la posibilidad de acceder a la procreación médicamente asistida está abierta sólo a parejas estériles o infértiles, así como a parejas donde el hombre está infectado con un virus de transmisión sexual. En cuanto al acceso al DGP, al reconocer el Gobierno explícitamente que en la legislación interna se prohíbe el acceso a este diagnóstico a cualquier persona, dicha prohibición constituye una injerencia en el derecho de este matrimonio al respeto de su vida privada y familiar.

Agregaron la falta de proporcionalidad de tal prohibición, a la luz de que el sistema legislativo italiano les autoriza una interrupción médica del embarazo cuando el feto está afectado por la patología de la que son portadores. Para

\footnotetext{
${ }^{33}$ Tribunal Europeo de Derechos Humanos, "Caso Costa y Pavan contra Italia", 2012. [Consulta: 20 de septiembre, 2016]. Disponible en http://www.loc.gov/law/foreign-news/article/european-court-of-human-rights-italy-ruling-on-embryo-screening/

${ }^{34}$ El diagnóstico genético preimplantatorio (DGP) es una técnica que se lleva a cabo durante un ciclo de fecundación in vitro. Permite, mediante una biopsia embrionaria, detectar alteraciones cromosómicas o genéticas de un embrión antes de su implantación en el útero de la persona. Su objetivo es asegurar una descendencia sana y acabar con la transmisión de patologias determinadas.
} 
justificar la injerencia, el Gobierno se basó en la preocupación de proteger la salud del niño y de la mujer, la dignidad y la libertad de conciencia de los profesionales médicos y el interés en evitar el riesgo de prácticas eugenésicas. No obstante, ante estos fundamentos, el Tribunal subrayó que:

El concepto de "niño" no puede ser equiparado al de "embrión”, no ve cómo la protección de los intereses mencionados por el Gobierno es coherente con la posibilidad ofrecida a los demandantes de un aborto terapéutico cuando el feto está enfermo, teniendo en cuenta las consecuencias que ello conlleva tanto para el feto, cuyo desarrollo es obviamente mucho más avanzado que el de un embrión como para la pareja de los padres, especialmente para la mujer.

Se remarca la falta de coherencia del ordenamiento jurídico italiano al prohibir la implantación sólo de los embriones no afectados por la enfermedad y permitirles abortar un feto afectado por ella. En conclusión, el Tribunal considera que la injerencia en el derecho al respeto de la vida privada y familiar ha sido desproporcionada, pues se violó el artículo 8 del Convenio.

De esta manera, si bien el TEDH no se ha expedido directa y especialmente sobre la naturaleza jurídica del embrión no implantado -como sí lo ha hecho su par interamericano en el caso Artavia- para resolver el conflicto suscitado a raíz de la restricción en la legislación italiana de TRHA, recurrió a la diferenciación de tres estadios en torno a la noción de vida humana: embrión, feto y niño. No pueden ser conceptos equiparables. El feto es un estadio mucho más avanzado que el del embrión.

\section{Palabras de cierre}

El presente trabajo tuvo por objeto visibilizar los derechos humanos comprometidos con las TRHA, con el fin de sentar las bases mínimas para estructurar y evaluar las legislaciones, políticas y otras acciones estaduales en este dinámico y complejo campo de estudio.

En este sentido, si bien las TRHA han sido originalmente desarrolladas como respuesta $o$ alternativa médica frente a la infertilidad de parejas heterosexuales que no podían acceder a la maternidad/paternidad por las vías "naturales" o "tradicionales", este uso primigenio se ha visto ampliamente desbordado. Esto se debe no sólo a los avances científicos-tecnológicos, sino también a los cambios sociales y culturales en torno a los modos de entender y configurar familias y proyectos parentales. 
Tanto los organismos internacionales con sus observaciones, como los tribunales regionales de derechos humanos con sus sentencias, evidencian y acompañan este viraje a la hora de interpretar el alcance de las TRHA. De este modo, se pasa de un paradigma exclusivamente médico o de salud en sentido restringido que entendía el acceso a las TRHA únicamente como un paliativo ante la infertilidad en parejas heterosexuales, evolucionando hacia una idea más amplia en dos sentidos: a) al entender que el derecho implica no sólo la salud física sino también la psíquica, cualquiera que sea la orientación e identidad sexual de la persona y $b$ ) al admitir que el derecho a la salud es sólo uno de los tantos derechos humanos que involucran las TRHA.

Esta es la perspectiva obligada a la hora de subsanar los vacíos legales en cuanto a las TRHA, materia aún pendiente de regulación en muchos Estados de América Latina. A la par, constituye una herramienta hábil para evaluar la corrección o no de las normativas existentes. Desde otra óptica, sería el modo de medir cómo los Estados cumplen o incumplen con sus responsabilidades en el plano regional-internacional, de conformidad con el control de convencionalidad que les cabe a partir del resonado caso Myrna Mack Chang vs. Guatemala de la CIDH, del 25 de noviembre de 2003 y todo su desarrollo hasta estos días. ${ }^{35}$ En definitiva, ratificar tratados de derechos humanos tiene sus ventajas y sus desafíos.

\section{Bibliografía}

Bergel, Salvador Darío, "Bioética”, en Salvador Darío Bergel, Lily Rosa Flah, Marisa Herrera y Eleonora Lamm, Bioética en el Código Civil y Comercial de la Nación, Buenos Aires, Thomson Reuters - La Ley, 2015.

ChÁvez, Valeria, "Por primera vez se hará un trasplante de útero en Argentina", Infobae. [Consulta: 17 de septiembre, 2016]. Disponible en: http://www.infobae. com/2016/03/11/1796228-por-primera-vez-se-hara-un-trasplante-uteroargentina/

CIDH, "Artavia Murrillo y otros vs. Costa Rica”. [Consulta: 17 de septiembre, 2016]. Disponible en: http://www.corteidh.or.cr/docs/casos/articulos/seriec_257_ esp.pdf

\footnotetext{
${ }^{35}$ Midón expresa: "Todos los publicistas coinciden en afirmar que la primera vez que se utilizó la frase 'control de convencionalidad' en una sentencia de la CIDH, fue en el caso 'Myrna Mack Chang vs. Guatemala', ocasión en el que en su voto concurrente razonado, el juez García Ramírez sostuvo que 'no es posible seccionar internacionalmente al Estado obligar ante la Corte sólo a uno o algunos de sus órganos, entregar a éstos la representación del Estado en el juicio -sin que esa representación repercuta sobre el Estado en su conjunto- y sustraer a otros de este régimen convencional de responsabilidad, dejando sus actuaciones fuera del control de convencionalidad que trae consigo la jurisdicción de la Corte Internacional". Mıdón, Marıo, Control de Convencionalidad, Buenos Aires, Astrea, 2016, p. 73.
} 
CIDH, “Atala Riffo y Niñas vs. Chile”. [Consulta: 17 de septiembre, 2016]. Disponible en: http://corteidh.or.cr/docs/casos/articulos/seriec 239 esp.pdf

CIDH, “Fornerón e hija vs. Argentina”. [Consulta: 17 de septiembre, 2016]. Disponible en: http://corteidh.or.cr/docs/casos/articulos/seriec_242_esp.pdf

Comité de Derechos Económicos, Sociales y Culturales, "The right to sexual and reproductive health (article 12 of the International Covenant on Economic, Social and Cultural Rights)", Colectivo Derecho de Familia. [Consulta: 16 de septiembre, 2016]. Disponible en http://www.colectivoderechofamilia. com/wp-content/uploads/2015/04/Observaci\%C3\%B3n-N-22-DESC_Derechos-sexuales-y-Reproductivos-02-05-2016.pdf

Consejo de EuRopa, "Convenio sobre los Derechos Humanos y la Biomedicina”. [Consulta: 17 de septiembre, 2016]. Disponible en: http://www.colmed2.org.ar/ images/code04.pdf

"Diego García Sayán habla sobre la Corte IDH en entrevista con el Mercurio Legal", Universidad de Chile. [Consulta: 16 de septiembre, 2016]. Disponible en: http://www.cdh.uchile.cl/noticias/detalle.tpl?id=20130722154614

Herrera, Marisa y Lamm, Eleonora, "Técnicas de Reproducción Humana Asistida", en Salvador Darío Bergel, Lily Rosa Flah, Marisa Herrera y Eleonora Lamm, Bioética en el Código Civil y Comercial de la Nación, Buenos Aires, Thomson Reuters - La Ley, 2015.

Kemelmajer de Carlucci, Aída y Herrera, Marisa, "Una voz autorizada del ámbito regional manda no discriminar en razón de la orientación sexual”, La Ley, 2012.

López GuerRa, Luis, "El Sistema Europeo de Protección de Derechos Humanos”. [Consulta: 20 de septiembre, 2016]. Disponible en: https://www.upf.edu/dhes-alfa/materiales/res/pmdh_pdf/PMDH_Manual.165-186.pdf

Manzano Barragán, Iván, "La jurisprudencia del Tribunal Europeo de Derechos Humanos sobre orientación sexual e identidad de género", Revista Española de Derecho Internacional, vol. 46, No. 2, Madrid, julio-diciembre 2012.

Midón, Mario, Control de Convencionalidad, Buenos Aires, Astrea, 2016.

NACIONES UnIDAS, "Declaración sobre la utilización del progreso científico y tecnológico en interés de la paz y beneficio de la humanidad", 1975. [Consulta: 17 de septiembre, 2016]. Disponible en: http://www.ohchr.org/SP/ProfessionaIInterest/Pages/ScientificAndTechnologicalProgress.aspx

Naciones UnidAs, "Informe de la Conferencia Internacional para la Población y el Desarrollo", Egipto, 1994. [Consulta: 17 de septiembre, 2016]. Disponible en: https://www.unfpa.org/sites/default/files/pub-pdf/icpd_spa.pdf

Tribunal Europeo de Derechos Humanos, "Caso Costa y Pavan contra Italia”, 2012. [Consulta: 20 de septiembre, 2016]. Disponible en http://www.loc.gov/law/ foreign-news/article/european-court-of-human-rights-italy-ruling-onembryo-screening/ 
Tribunal Europeo de Derechos Humanos, “E. B. vs. France”. [Consulta: 20 de septiembre, 2016]. Disponible en: http://www.1cor.com/1315/?form_1155.replyids=1129 Tribunal Europeo de Derechos Humanos, “Frette $v$ s. France (36515/97)”, 2002. Disponible en: http://www.equalrightstrust.org/ertdocumentbank/frette $\% 20 \mathrm{v} \% 20$ france.pdf

Tribunal Europeo de Derechos Humanos, "Salgueiro Da Silva Mouta vs. Portugal", 1999. [Consulta: 20 de septiembre, 2016]. Disponible en http://www.gddc.pt/ direitos-humanos/portugal-dh/acordaos/traducoes/Trad_Q33290_96.pdf

Tribunal Europeo de Derechos Humanos, 19/02/2013, “X and Others vs. Austria”, La Ley, 2013.

TEDH y CIDH, "Diálogo Transatlántico: Selección de Jurisprudencia del Tribunal Europeo y la Corte Interamericana de Derechos Humanos", Wolf Legal Publishers, 2015. [Consulta: 20 de septiembre, 2016]. Disponible en: http://www.echr. coe.int/Documents/Dialogue_Across_Atlantic_SPA.pdf

unEsco, “Declaración Universal de Bioética y Derechos Humanos”, 2005. [Consulta: 17 de septiembre, 2016]. Disponible en: http://portal.unesco.org/es/ev.phpURL_ID=31058CtURL_DO=DO_TOPICEURL_SECTION=201.html 